\title{
Geósfera, exposición de Pinturas Poligonales
}

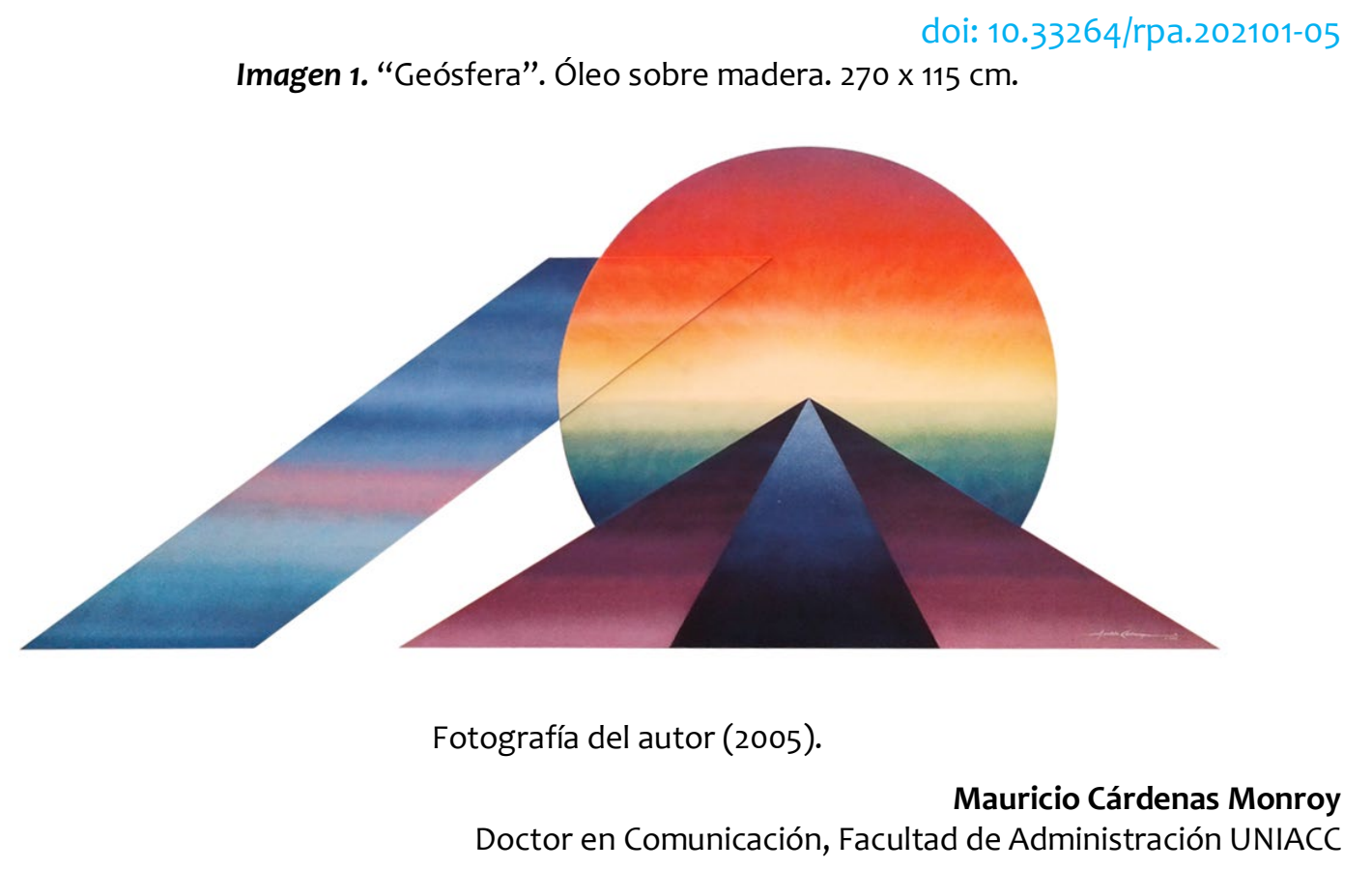

\section{Resumen}

El siguiente artículo es una breve narración acerca del proceso creativo experimentado por el autor en el ámbito estético de la pintura, expresado en un proyecto titulado "Geósfera". Este proyecto consiste en una exposición de pinturas poligonales, vale decir, pinturas cuyo formato no es rectangular ni cuadriculado (como lo es en la tradición pictórica) sino que se compone de áreas geométricas o polígonos que refieren a un nuevo y mayor polígono: Geósfera, la esfera de la Tierra y de la Geometría. Hasta ahora, esta exposición comprende un total de 15 pinturas poligonales, las que se pueden apreciar en su integridad en la página web www.geosfera.cl de reciente publicación.

Palabras clave: Pintura poligonal, Geósfera, composición visual.

\section{Abstract}

The following article is a brief narration about the creative process experienced by the author in the aesthetic field of painting expressed in a project entitled "Geosphere". This project consists of an exhibition of polygonal paintings, that is to say, paintings whose format is not rectangular or squared (as it is in the pictorial tradition) but rather is made up of geometric areas or polygons that refer to a new and larger polygon: Geosphere, the sphere of the Earth and Geometry. So far, this exhibition comprises a total of 15 polygonal paintings, which can be seen in their entirety on the recently published website www.geosfera.cl.

Keywords: Polygonal painting, geosphere, visual composition. 


\section{Proyecto de innovación morfológica}

El año 2001 inicié esta experiencia creativa y de innovación en el contexto de la Pintura, en cuyo proceso me propuse superar la tradicional estructura de composición visual y pictórica sujeta al tradicional formato rectangular o cuadrado. Primero, comencé a experimentar en el croquis para, luego, probar con papeles de colores recortados en diversas formas geométricas, las que combiné formando libremente múltiples composiciones formales que dieron lugar a una nueva morfología visual. Pronto descubrí que no solo era factible crear múltiples alternativas composicionales, sino que, más bien, se abren infinitas posibilidades de composición visual tanto en el ámbito de la forma como del color. Sorprendido por estos resultados experimentales, decidí trasladar estas composiciones al formato material y sólido que permite la madera, en tamaños que promedian los 2 metros de largo para cada pintura. Así, inicié este proceso experimental y creativo que expongo aquí en esta síntesis, en la que resumo veinte años de labor ininterrumpida.

¿A qué responde este cambio, esta búsqueda de superación de un formato que nos es tan cómodo, como son las formas rectangulares o cuadriculadas? ¿Cuál es el propósito de formular este cambio de morfología? ¿Reviste alguna significación de fondo?

En principio, no se trata de eliminar o invalidar estéticamente las formas cuadriculadas. Se trata, más bien, de explorar nuevas posibilidades de interrelación formal, que aparecen variadas, múltiples e infinitas tanto en nuestro Universo natural así como en el mundo cultural y estético creado por la humanidad. Luego, nos encontramos con el alto nivel de proporción que juega la imagen en la percepción y retención sensorial en el ser humano: un 85 \% de la información que capta y retiene nuestro cerebro es imagen, según Tobii Technologies (2008). Por lo tanto, literalmente pensamos con imágenes. Mientras tanto, nuestro sistema óptico selecciona lo que vemos y nuestra memoria visual reconstruye escenas, pues interpretamos nuestro mundo a partir de nuestra percepción visual.

Surge, desde aquí, una interrogante esencial a partir de la importancia que juega nuestra visión: ¿Por qué hemos de encuadrar nuestra mirada en relación a una estructura rectangular o cuadrada? ¿Se trata de una estructura funcional, luego mental, de un paradigma visual heredado de la modernidad? Pues, si analizamos la estructura óptica de nuestra visión ocular veremos que tampoco es cuadrada ni rectangular sino que presenta, más bien, una estructura ovalada, en directa relación y coherencia con la curvatura del espacio y, en particular, con nuestra tercera dimensión, formada de planetas, satélites y estrellas, constelaciones y galaxias. 
Curvatura que se manifiesta en nuestra Tierra y sus múltiples formaciones naturales, tanto a escala humana como en los niveles microscópicos, en cuya configuración visual casi no existen formas cuadriculadas.

A esta infinitud natural hemos de agregar la vasta morfología proveniente de la creatividad humana, tradicionalmente expresada en el ámbito físico, hoy además virtual, en las que emerge, por igual, una amplia morfología nueva y diferente. Así, en el arte digital, han surgido un conjunto de universos virtuales que juegan con fractales que se combinan con mundos surreales, donde la imaginación ya no encuentra límite alguno para manifestar libremente su creatividad.

Por su parte, en el contexto físico de las artes espaciales y en esta nueva mirada de apertura, destaca la revolución arquitectónica que surge con Oscar Niemeyer, Jörn Utzon, Santiago Calatrava, Zaha Hadid, Frank Gehry, Norman Foster y Bjarke Ingells, entre otros arquitectos, quienes exponen actualmente una transformación profunda respecto de las usuales concepciones acerca de nuestro hábitat, en que los paralelepípedos comienzan a desaparecer y a ser reemplazados por domos, pirámides curvadas y las más diversas configuraciones poliédricas entre los volúmenes de sus estructuras orgánicas.

¿Por qué, entonces, la pintura, el arte de la forma y el color, habría de permanecer indiferente a estos cambios? A su vez, respecto de este nuevo paradigma arquitectónico: ¿Cómo se integrarán a estas nuevas configuraciones tridimensionales las tradicionales formas de la pintura, escultura, instalaciones y diversos objetos de arte en tanto concebidos dentro de una matriz cuadriculada? Se trata, entonces, no solo de un cambio estético de superficie sino de un cambio de paradigma estético, visual, mental y cultural. De una transformación que invita a reemplazar una estructura cultural gastada y rígida por otra nueva, abierta y flexible, en la disposición de sus trayectorias formales. Cambio que prepara un futuro radicalmente distinto a la tradición histórica de la modernidad en relación al diseño de sus ciudades y que se ha venido desarrollando a través de las décadas en que se ha expresado la actual posmodernidad que, a su vez, es transición y antesala de una era nueva que se avizora en el horizonte de la actual evolución humana.

A partir de este desafío de innovación formal surge el actual proyecto titulado Geósfera, como un proceso de experimentación abierto a la propia configuración de cada composición pictórica, por medio de módulos geométricos integrados en nuevas composiciones poligonales e interrelaciones formales.

Para mayor claridad en la apreciación de estos trabajos, se expone en la siguiente ilustración la relación entre la composición pictórica y la figura humana, así como también el resultado de su instalación sobre un muro. 
Imagen 2. Pintura poligonal “Energía” y el autor, en referencia a la instalación física de la obra.

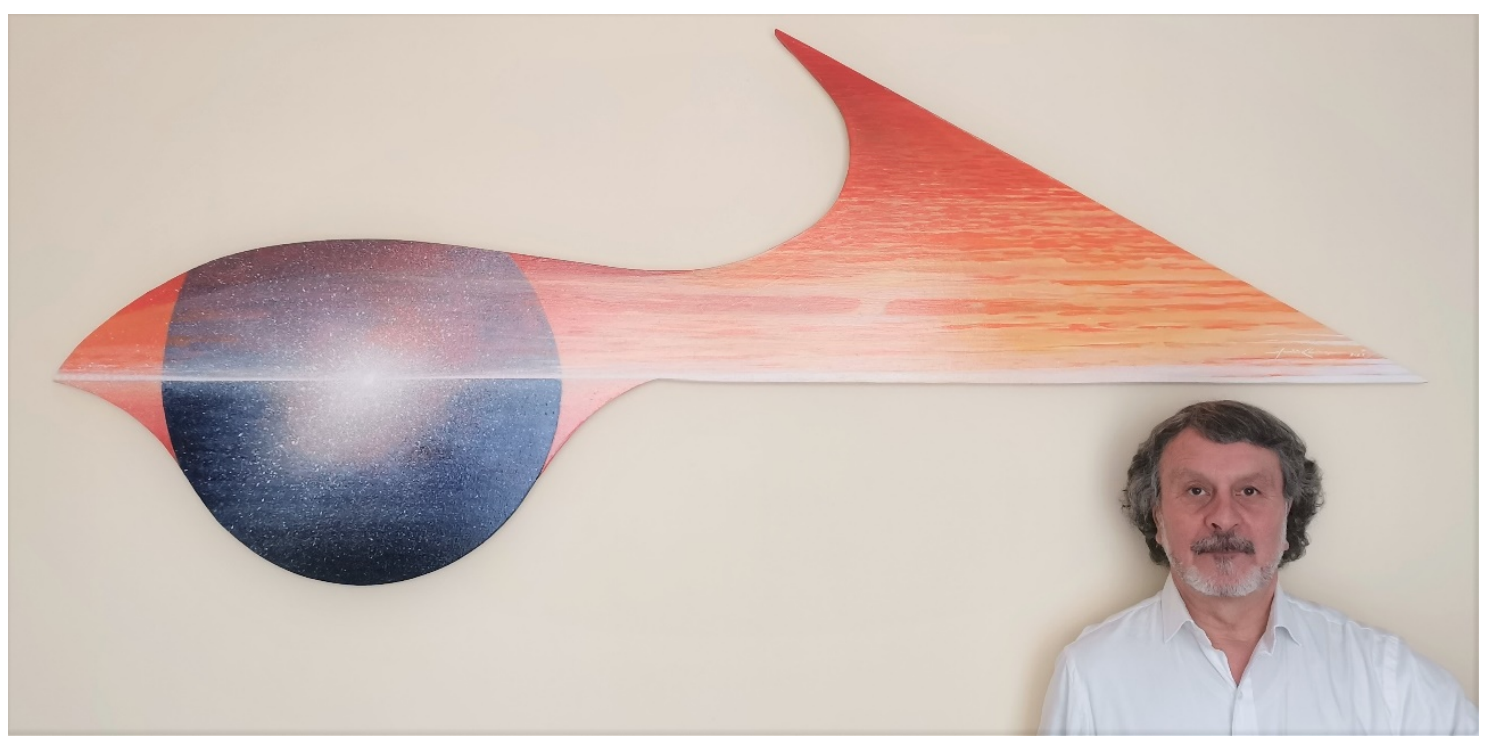

Fuente: Fotografía del autor (2021).

\section{Proceso de ejecución del proyecto}

Al comenzar el proceso de ejecución de este proyecto se presentó, para cada obra, un nuevo desafío de carácter técnico traducido, primeramente, en una fase inicial de intenso estudio de diseño, seguido de trabajos de carpintería en los cortes y uniones de los polígonos entre sí, a partir de un plano exacto de sus medidas y proporciones. Luego, la acción de efectuar dos capas de pintura blanca que, una vez secas, permiten llevar a cabo el proceso del color, vale decir, la creación pictórica propiamente tal.

Un segundo desafío lo constituye asegurar la forma de colgar estos polígonos en un muro, del mismo modo que lo hiciéramos con una pintura tradicional. Para ello, es necesario disponer, en cada reverso de las pinturas, de un marco rectangular que permita su fácil instalación sobre la pared, como se puede apreciar en la siguiente ilustración (Ver imágenes 3 y 4).

Imagen 3. Alborada. Óleo sobre madera. 240 x $160 \mathrm{~cm}$.

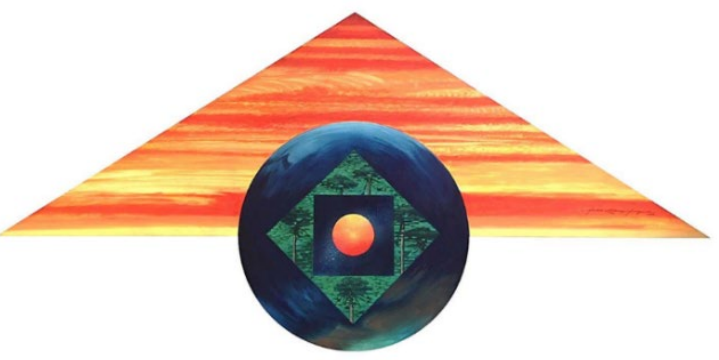

Fotografía del autor (2001). 
Imagen 4. Marco rectangular en su reverso.

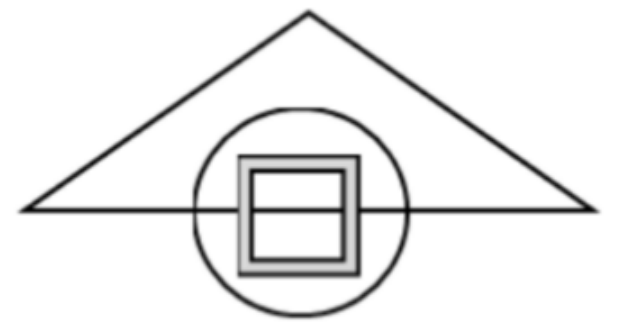

Diseño del autor.

\section{Geósfera, esfera de la Tierra, nuestra dimension}

De este modo, en este proyecto se integra, en su forma y color y desde la primera de estas composiciones, los cuatro elementos que proporcionan la biósfera de nuestro planeta: una columna cálida que reproduce en cada amanecer y atardecer esa especie de fuego en el cielo; el espacio de mares, ríos y lagos que nos brinda el vital elemento del agua; el oxígeno, que forja nuestra atmósfera. Todos, elementos que posibilitan la existencia de campos y bosques verdes que manifiestan la esencia de la Tierra, que conectan a cada árbol con el Cosmos, entre océanos de luz y oscuridad, en su eterno girar en medio de espacios telúricos y cósmicos.

Hemos de tener presente aquí que el concepto de Geósfera, en el contexto científico, representa la escala geológica de la Tierra formada por sus cinco capas materiales o minerales: la atmósfera; la corteza terrestre, donde se ubica nuestra superficie y esfera de acción a escala humana; el manto, situado a $70 \mathrm{~km}$. bajo la corteza terrestre; el núcleo externo (bajo $2.900 \mathrm{~km}$.); y el núcleo interno (bajo $5.140 \mathrm{~km}$. y a una temperatura de 6.000 grados centígrados).

Sin embargo, la Geósfera no es solo esa escala geológica material, sino que es nuestra dimensión visual, la escala humana de proporción espacial en referencia a la propia medida y tamaño de nuestro cuerpo. Desde que surge la Geometría, como conjunto de medidas, formas y proporciones de todos los objetos sólidos, ciencia que nace en el Antiguo Egipto y se transforma en arte aplicado acorde a una estética en la Grecia clásica, ha experimentado fases progresivas de desarrollo hasta llegar a su actual fase de transformación en el surgimiento de nuevos paradigmas facilitados por otra revolución - tecnológica - que a su vez incide directamente en la velocidad, precisión y calidad de todo lo que se diseña y comunica.

Geósfera es, por ende, aquella amplia gama de manifestaciones abstractas y naturales de la Geometría, puesta de manifiesto en sus formas cerradas y estructuradas, presentes en todos los niveles de las configuraciones naturales que nos conectan con el Universo, concebido como un gigantesco huevo cósmico 
poblado de galaxias globulares y espirales, átomo macroscópico formado por millones de sistemas solares concéntricos y cuerpos celestes dotados en su interior de capas circulares e ígneos núcleos también esféricos. Encadenamiento energético que prosigue en el tejido de las estructuras naturales, que culminan en la configuración de la propia figura humana, para avanzar hasta el infinito ámbito microscópico del átomo, hacia su geometría radiante.

Imagen 5. Leonardo Da Vinci: El hombre de Vitruvio (1492).

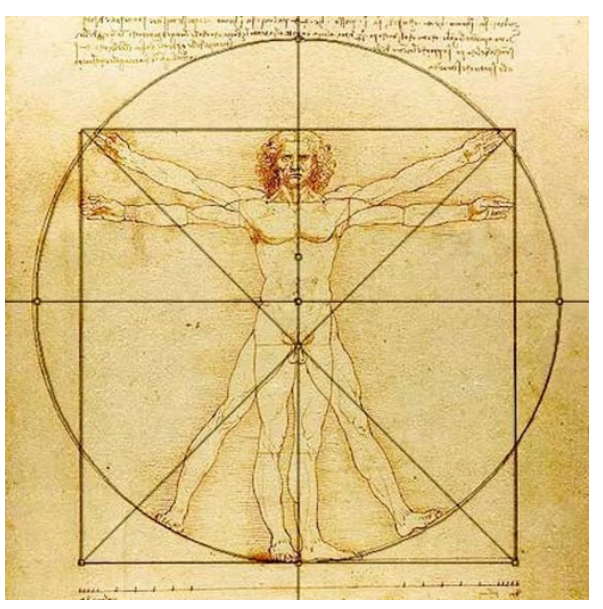

Fuente: artefeed.com (2018).

Imagen 6. Estructura simétrica y dinámica del átomo.

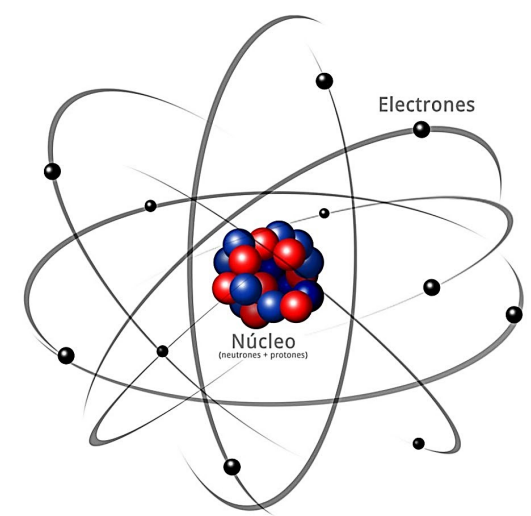

Fuente: comofuncionaque.com (2018).

\section{Significación estética y comunicacional}

Acorde a esta mirada, la presente exposición se expresa a través de gradaciones de color-espacio que refieren a diversos niveles cósmicos de nuestra realidad visual, avanzando hacia una nueva síntesis de las formas nacidas de la Geometría y que nos abren paso al surgimiento de un nuevo arte, dotado de nuevas combinatorias formales que reemplazarán el aún vigente formato rectangular y cuadriculado al que 
estamos habituados. Este proceso de transformación ya se puede apreciar claramente en la revolución arquitectónica y de diseño que se experimenta y aplica en diferentes puntos del planeta, como expresión de una nueva relación entre el hábitat, el espacio y el medio ambiente, que expone una cultura naciente desde estos procesos de creatividad e innovación morfológica, estética y comunicacional, en tanto, invita a una nueva forma de relacionarnos y de compartir un presente y futuro compartido.

Por su parte, la Pintura comienza a profundizar en su propia capacidad de exploración de su universo interior y exterior, en su propia autonomía expresiva y, con ello, en sus propias e intrínsecas potencialidades de futuro en tanto, en esencia, es el arte del color, de la forma, del espacio y de las múltiples significaciones que emergen desde sus contenidos visuales y conceptuales. Más bien, desde el mensaje que nos envía en su intencionalidad creativa cada obra, cada composición pictórica. De ese mensaje que emerge explícito o implícito desde sus valores estéticos y que en más de algún caso se ha transformado en una interrogante que nos plantea su autor o autora.

En el caso de la exposición que aquí se presenta, el mensaje que emite responde al llamado de participar y de integrarnos - como sociedad del conocimiento y en la era de la comunicación - en esta unión y apertura hacia el Cosmos que, a su vez, convoque a una nueva integración humana y cultural, decisiva para nuestra propia evolución como especie humana. Su objetivo es aportar a la reintegración visual del mundo, dar un nuevo giro en la amplitud de percepción del Universo y del ser humano mismo, en forma constituyente e integradora que se manifiesta desde el microcosmos cuántico hasta las dimensiones cósmicas que hoy explora la ciencia del Siglo XXI.

Esta relación, entre el ser humano y el Cosmos evidentemente no es nueva y tiene antecedentes notables en antiguas culturas de todo el mundo, entre las que hemos de consignar nuestras propias culturas ancestrales precolombinas, a las que en esta serie pictórica se representa en una obra titulada "Indoamérica" (2017), con la presencia, en el polígono superior, de un Telar Mapuche, cubierto de símbolos geométricos. Luego, en su centro, el Calendario Maya y sus ocho estaciones del año. $\mathrm{Y}$, en el polígono inferior, se representa al colibrí, figura de 300 metros de largo que sobresale en el conjunto de geoglifos de Nasca. En todas estas expresiones culturales precolombinas se conecta geometría, naturaleza, espacio y tiempo, testimonio de culturas íntimamente conectadas con las fuerzas cósmicas y de la Tierra. 
Imagen 7. Indoamérica. Acrílico sobre madera. 222 x $172 \mathrm{~cm}$.

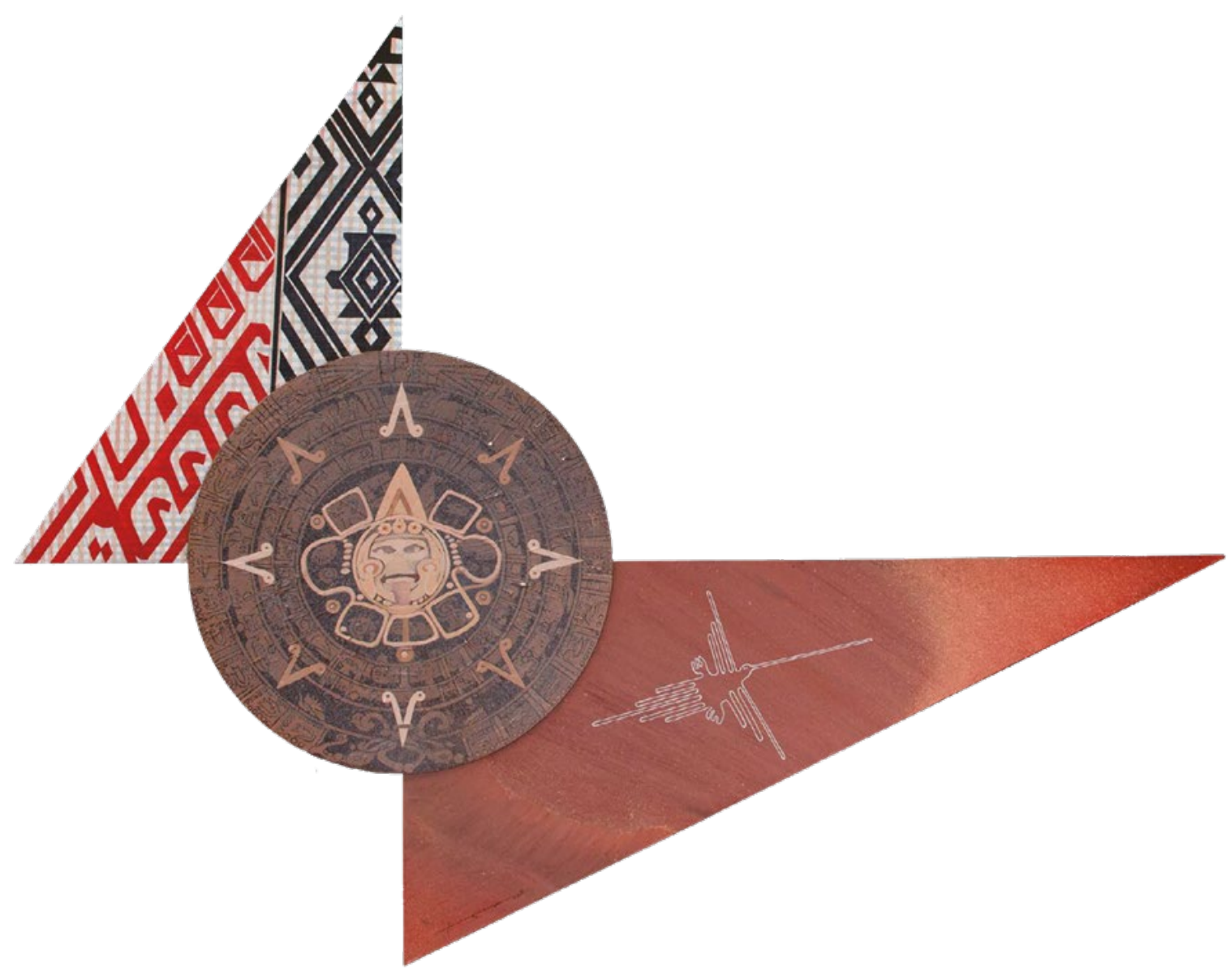

Fuente: Fotografía del autor (2017)

Síntesis que reaparece en “El árbol de la vida” (2020), en cuya pupila se sitúa el centro energético de nuestra galaxia, la Vía Láctea, y su constante explosión de energía que se expande hacia el Sol y el aire, en medio de un eterno renacer del Ave Fénix, posado en la copa de un fresno, como nos lo narra el mito del Yggdrasil, el árbol primigenio. Este eterno retorno, en forma constante a través del tiempo, denota nuestros sucesivos cambios, transformaciones y evoluciones hacia nuevas etapas $y$ experiencias, físicas, psicológicas y emocionales, en medio de ciclos vitales y existenciales. La vida se expresa como un constante proceso de transformación, en continuo movimiento, cada vez más dinámico y energético. $Y$ todo ello inmerso en un ojo. Un ojo que capta, observa, mide e interpreta, atento al esplendor de la vida. 
Imagen 8. "El árbol de la vida". Acrílico sobre madera. 225 x 120 cm.

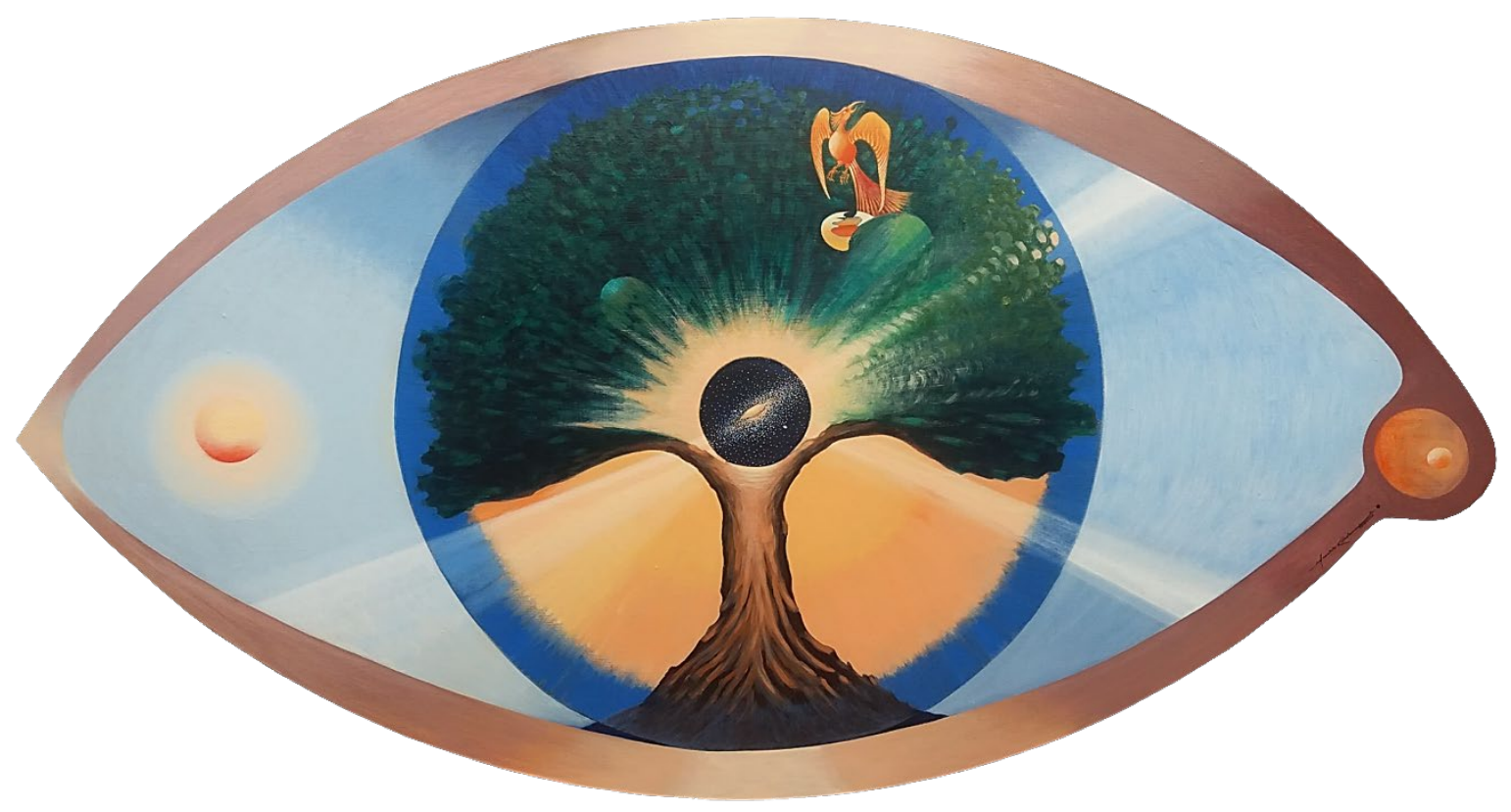

Fuente: Fotografía del autor (2020).

\section{Referencias}

Cárdenas, M. (2001-2021). Geósfera. Proyecto de Creación Pictórica. www.geosfera.cl

Registro de Propiedad Intelectual No. 177.902, Departamento de Derechos Intelectuales, Servicio Nacional del Patrimonio Cultural.

Tobii Technologies (2008). Estudio de percepción humana. www.udeye.de

Fig. 5. El hombre de Vitruvio.

https://artefeed.com/hombre-vitruvio-da-vinci/

https://io.wp.com/artefeed.com/wp-content/uploads/2018/08/leonardo-da-vinci-

vitruvio-hombre-3-1.jpg?resize $=1024 \% 2 \mathrm{C} 1024 \& s \mathrm{sl}=1$

Fig. 6. Estructura del átomo.

https://comofuncionaque.com/que-es-un-atomo-y-un-electron/

https://comofuncionaque.com/wp-content/uploads/2016/01/partes-de-un-

atomo1.jpg?ezimgfmt=ng:webp/ngcb1 


\section{Mauricio Cárdenas Monroy}

Doctor en Comunicación, Universidad UNIACC (2011) y Licenciado en Teoría e Historia del Arte, Universidad de Chile (1985). Se desempeña como decente de las asignaturas de Comunicación Social e Interpersonal en la Universidad UNIACC. Ha realizado exposiciones pictóricas desde 1987 hasta el presente y publicado dos textos de estudio en forma digital: " Prospectiva, clave del desarrollo sustentable" (2014) y "Focos y trayectorias de la Comunicación Social" (2015). Y un ensayo en formato digital e impreso: "Visión prospectiva para una Nueva Constitución" (Rutalfuturo, 2020) a modo de aporte reflexivo al actual proceso de transformación social, política y cultural que vive Chile. 